\title{
DEAD SPACE REDUCTION CLOSED THORACOPLASTY IN CHRONIC EMPYEMA THORACIS PATIENTS OF EARLY YOUNG AGE GROUP
}

\author{
Praveen Sharma ${ }^{1}$, Deepesh Guptaㄹ , R. P. Kaushal ${ }^{3}$, Ankur Joshi ${ }^{4}$ \\ ${ }_{1}^{1}$ Associate Professor, Department of Cardiothoracic and Vascular Surgery, Gandhi Medical College, Hamidia Hospital, Bhopal, \\ Madhya Pradesh. \\ ${ }_{2}^{2}$ Associate Professor, Department of Anaesthesia, Gandhi Medical College, Hamidia Hospital, Bhopal, Madhya Pradesh. \\ 3 Professor, Department of Cardiac Anaesthesia, Gandhi Medical College, Hamidia Hospital, Bhopal, Madhya Pradesh. \\ ${ }^{4}$ Assistant Professor, Department of Social and Preventive Medicine, All India Institute of Medical Sciences, Bhopal, \\ Madhya Pradesh.
}

\begin{abstract}
BACKGROUND
ABSTRACT

The social stigma of chronic empyema thoracis treated with open window thoracostomy (OWT) has significant negative impact on psychosocial well-being, especially in early young age group patients. So, evaluation of better alternative of dead space reduction closed thoracoplasty method was done by the author.

Aims and Objectives- To evaluate standard easily reproducible surgical method to cure and control chronic empyema thoracis other than open window thoracostomy in early young age group patients in central India.
\end{abstract}

\section{MATERIALS AND METHODS}

Dead space reduction closed thoracoplasty was performed in 44 patients of chronic empyema thoracis between the age group of 13 and 25 years by conventional thoracoplasty (Alexander type), tailoring thoracoplasty and Schede thoracoplasty. Patients were evaluated in terms of weight gain, chest x-ray, air leak and column movement in ICD and pus culture sensitivity at regular intervals. Targeted dead space reduction is achieved excellently when column movement is less than $5 \mathrm{~cm}$ and acceptable when between 5 and $10 \mathrm{~cm}$. Absence of air leak even on coughing (excellent) and only on coughing (acceptable) in patent intercostal drainage tube. Statistical Analysis- By student's t-test, repeated measure ANOVA test for difference of mean, confidence interval with standard error estimation, 'p' value and percentage also.

Setting and Design- A hospital-based prospective longitudinal study as all the enrolled patients are followed up at designed time.

\section{RESULTS}

Chronic empyema thoracis of 40 patients was cured and controlled with dead space reduction thoracoplasty, whereas 4 patients with multi-drug resistance tuberculosis (MDR TB) did not cure, so they further required other modalities.

\section{CONCLUSION}

Patients with persistent infection and poor weight gain have high failure rate in dead space reduction closed thoracoplasty.

\section{KEYWORDS}

Chronic Empyema thoracis, Broncho-Pleural Fistula, Dead Space Reduction Closed Thoracoplasty, Open Window Thoracostomy.

HOW TO CITE THIS ARTICLE: Sharma P, Gupta D, Kaushal RP, et al. Dead space reduction closed thoracoplasty in chronic empyema thoracis patients of early young age group. J. Evolution Med. Dent. Sci. 2018;7(14):1772-1777, DOI: $10.14260 /$ jemds/2018/400

\section{BACKGROUND}

Empyema thoracis is the collection of purulent material in the pleural space. The treatment of empyema thoracis is done mainly by closed tube drainage with underwater sealed system along with antibiotics and other supportive medicines. In spite of above management, many patients of empyema are not cured and converted into chronic empyema. Chronic empyema is associated with or without bronchopleural fistula. Chronic empyema is an extremely morbid pathology with a high mortality rate. ${ }^{1,2}$ Thoracotomy with decortication is indicated when underlying pulmonary

'Financial or Other Competing Interest': None.

Submission 05-03-2018, Peer Review 18-03-2018,

Acceptance 21-03-2018, Published 02-04-2018.

Corresponding Author:

Dr. Praveen Sharma,

Department of Cardiothoracic and Vascular Surgery,

Gandhi Medical College, Hamidia Hospital,

Bhopal, Madhya Pradesh.

E-mail: drpraveen77@gmail.com

DOI: $10.14260 /$ jemds $/ 2018 / 400$

\section{(c) $(1) \$$}

parenchyma is normal. Lung resection is used to remove the destroyed lung tissue. But dead space is always a significant problem in these chronic empyema patients. The dead space becomes highly significant problem when associated with bronchopleural fistula. These communications between bronchus to pleural cavity are at high risk of bronchial aspiration, adult respiratory distress syndrome which lead to high mortality. $3,4,5$ The principle of management is to protect the contralateral lung from the spillage of pleural fluid, control of empyema with complete drainage and antibiotics, identification and closure of fistula and dead space obliteration along with nutritional rehabilitation.6,7 The management depends on the size of bronchopleural fistula and clinical condition of the patients.8,9,10 Open window thoracostomy is an old procedure, which is still considered as procedure of choice in these situations of chronic empyema with or without bronchopleural fistula associated with severe sepsis, acute septic shock, multi-organ dysfunction and other co-morbid condition like diabetes, hepatitis etc. Open window thoracostomy is associated with psychosocial stigma, especially in young age group patients due to a large opening 
present in thoracic wall which needs daily dressing. ${ }^{11-14}$ To address the negative psychosocial impact and poor quality of life in these chronic empyema thoracis patients treated with open window thoracostomy, extensive literature search was done by author to find evidence based alternative surgical method.

The study of Hopkins ${ }^{15,16}$ et al rejuvenated the idea of modern use of thoracoplasty. So, author used the principle of collapse therapy to treat chronic empyema in especially early young age group patients, to eradicate the social stigma of open window thoracostomy. The basic principle followed in dead space reduction thoracoplasty is either lung expands enough to reach the chest wall or chest wall moves towards the partially expanded diseased lung.

\section{Objective of this Study}

To evaluate standard, easily reproducible surgical method to cure and control chronic empyema thoracis other than open window thoracostomy in early young age group patients in central India by exploring and examining the dead space reduction closed thoracoplasty on the basis of the selected parameters. The probable impact of this study (not direct access) may be considered in term of addressing the psychosocial stigma of Open Window Thoracostomy.

\section{MATERIALS AND METHODS}

This hospital-based prospective longitudinal study was conducted in the Department of Cardiothoracic and Vascular Surgery of a tertiary care centre, Gandhi Medical College and Hamidia Hospital, Bhopal, MP, from January 2013 to December 2016. This prospective longitudinal single centre study representing the patient population of central India. The inclusion criteria for the study were chronic empyema (of more than 8 weeks with intercostal drainage tube) patients with age group of 13 to 25 years. All 44 patients who fit into the criteria between specified duration were recruited for the study after obtaining the written informed consent. These enrolled patients were followed up time to time as per designed study protocol.

\section{Statistical Analysis Method}

All the quantitative variables were summarised by mean and standard deviation, while all the Categorical variables were shown by frequency distribution. For comparison of two groups we used student's ' $t$ ' test and for more than two groups (repeated observation on weight gain by the participant) we used repeated measure ANOVA test. The acceptable limit of type-I error was set on $5 \%$ and any value beyond 95\% confidence interval was deemed significant.

Patients suffering from tuberculosis were on antitubercular treatment (ATT) with completion of intensive phase of ATT. They had sputum negative for AFB too. Periodic evaluation of patients was done in terms of weight gain, chest x-ray, air leak and column movements in ICD at regular intervals. Pus culture and sensitivity was performed before and after 2 weeks of procedure.

When chest x-ray showed radiolucency with no bronchopulmonary markings considered as dead space, if radiolucency present in more than $50 \%$ it is large, $25 \%-50 \%$ is moderate and less than $25 \%$ is mild of affected side of thoracic cavity volume.
Results were considered good when empyema resolved, sputum remained AFB negative, there was weight gain of patients, in chest x-ray no/ mild dead space with absent hydro-pneumothorax, column movement of less than $5 \mathrm{~cm}$ (excellent), 5 - $10 \mathrm{~cm}$ (acceptable) and air leak absent even on coughing (excellent), air leak present only on coughing acceptable in both apical straight and basal angle ICD. For column movement basal angle ICD is more appropriate and for air leak straight apical ICD is considered more appropriate. Patency of ICD must be confirmed prior to evaluation.

Results were considered to be poor in persistent infection in the form of draining sinuses/ sinus, failure to obliterate dead space, recurrence of sputum positivity for AFB, absence of weight gain or presence of weight loss.

\section{Operative Procedure}

Author performed conventional thoracoplasty (Alexander type) sub-periosteal extrapleural posterolateral resection of sufficient ribs to obliterate the intrathoracic space, mainly in all dead space reduction thoracoplasty. Schede thoracoplasty was done in tubercular chronic empyema with moderate to near completely collapsed lung with tension suturing to approximate skin and extrathoracic muscle tissue. Tailoring thoracoplasty was done in patients of chronic empyema with associated pathology of bronchiectasis, infected hydatid cyst, mature teratoma and infected pleural cyst.

The operative procedure performed was rib resection in all the patients. The number of ribs resected varied from 2 to 6 ribs and the order of rib resection varied from second to seventh rib. Rib resection and decortication was performed in 34 patients, four patients underwent lobectomy with rib resection. Rib resection with dead space obliteration was performed in 2 patients. Excision biopsy with rib resection and decortication was performed in 4 patients, out of which two were with infected hydatid cyst, one with mature teratoma and one with infected pleural cyst. All patients have two intercostal drainage tube, one apical straight and second basal angle ICD.

\section{RESULTS}

Forty-four patients were enrolled for study, out of which 18 were males and 26 were females and mean age of 20.50 years was for males and 18.96 year was for females. There was statistically no significant difference in distribution of chronic empyema thoracis patients according to gender and age, $(\mathrm{p}=0.104)$.

Total 44 patients of chronic empyema thoracis in which 36 patients had tuberculosis (81.8\%), 4 patients had infected hydatid cyst $(9.1 \%), 2$ patients with bronchiectasis $(4.5 \%)$, one patient of mature teratoma $(2.3 \%)$ and one patient with infected pleural cyst with empyema $(2.3 \%)$.

Out of 44 patients, 24 had left-sided lung lesion (54.5\%) and 20 patients had right-sided lung lesion (45.5\%).

The patient's population was from low socio-economic status and few patients were associated with immunecompromised states like 3 patients were HBsAg positive and 2 were HIV positive.

Out of 44 patients, rib resection with decortication was done in 34 patients $(77.27 \%)$ and rib resection with lobectomy and rib resection with decortication with excision 
biopsy was done in 4 patients each $(9.1 \%+9.1 \%)$ and 2 patients underwent rib resection only (4.5\%) (Table 1).

In most of the patients, 3 and 4 ribs were resected. In 16 (36.4\%) patients 3 ribs were resected and in 12 (27.3\%) patients 4 ribs were resected. 6 ribs were resected in 4 patients (9.1\%).

Mean weight of both male and female patients significantly increased after thoracoplasty. It was $36.95 \pm 4.7$ $\mathrm{kg}$ at the time of enrolment. It increased with time and at 24 weeks increased to $42.83 \pm 5.9 \mathrm{~kg}$. There was highly significant difference in weight gain in both male and female patients $(p=0.001)$, (Table 2$)$.

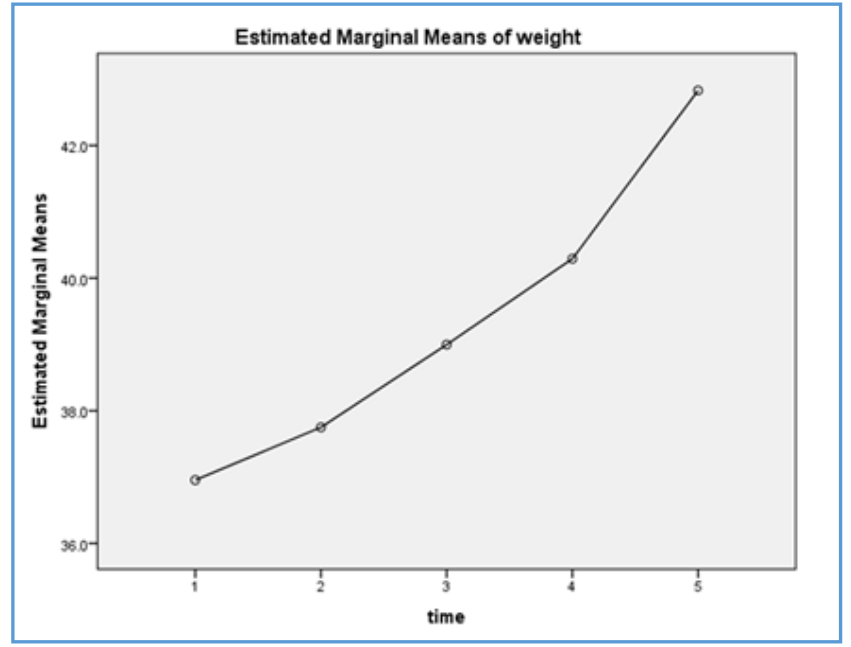

Profile Plots

Repeated measures of ANOVA with a Greenhouse-Geisser correction determined that mean weight differed statistically significantly between time points $(\mathrm{F}(62.05,180.33)=652.89$, $\mathrm{p}<0.0001$ ). Post hoc tests using the Bonferroni correction revealed that mean weight gain is significant at every time interval. Therefore, we can conclude the procedure elicits a statistically significant gain in mean weight at every time interval.

\begin{tabular}{l|r}
180.332 & 62.057
\end{tabular}

Pre-operatively, pus culture of patients showed growth of Klebsiella in 14 patients (31.8\%), pseudomonas in 12 $(27.3 \%)$, E. coli in $10(22.7 \%)$, Streptococci in $4(9.1 \%)$ and staphylococci and mixed bacteria in 2 patients each, which comprises $4.5 \%$ each. Post-operatively, after 2 weeks pus culture showed no growth in 33 patients (75\%) and 11 patients (25\%) showed growth.

Pre-operatively, chest $\mathrm{x}$-ray findings among chronic pleural empyema patients- among most of the patients, moderate collapse with hydro-pneumothorax were seen i.e. 25 (56.8\%) and near complete collapse with hydropneumothorax were seen in 15 (34.1\%) patients, (Table 3).

Table 4 reveals in all patients there was marked improvement post-operatively as in chest x-ray findings at different time interval among chronic pleural empyema patients. After 24 weeks post-operatively no dead space with no hydro-pneumothorax was found in $32(72.7 \%)$ patients, while mild-to-moderate dead space with no hydropneumothorax in 12 (27.3\%).
There was significant improvement in expansion of lung, (less than $5 \mathrm{~cm}$ ). Column movement from straight apical intercostal drainage tube (ICD) at 6 weeks post-operatively in 35 patients $(79.5 \%)$, whereas 5 patients had $5-10 \mathrm{~cm}$ column movement considered acceptable. Near similar results were found in basal angle ICD tubes (Table $5 a, 5 b$ ).

Air leak from straight apical ICD was absent even on coughing in $39(88.6 \%)$ patients and in $1(2.3 \%)$ patient was present on coughing only, while only $4(9.1 \%)$ had air leak with deep expiration. In basal angle ICD, $39(88.6 \%)$ patients had no air leak and 5 patients had air leak on coughing only at 4 weeks (Table 6a, 6b).

On the basis of Table $5 a, 5 b, 6 a, 6 b$ represent targeted dead space reduction is achieved excellently in 36 patients, whereas acceptable in 6 patients which show column movement less than $10 \mathrm{~cm}$ in basal angled ICD. Similarly, targeted dead space reduction and cure and control of lung parenchymal disease is achieved excellently in 39 and acceptable in 1 patient, which show absent air leak even on coughing in 39 and in one only on coughing.

40 patients were cured and controlled with dead space reduction thoracoplasty, whereas 4 patients with MDR TB were not recovered, so they further required other modalities like open window thoracostomy etc. afterward on follow-up.

\begin{tabular}{|c|c|c|}
\hline Type of Operation & Number & Percentage \\
\hline Rib resection & 2 & $4.5 \%$ \\
\hline Rib resection with decortication & 34 & $77.27 \%$ \\
\hline Rib resection with lobectomy & 4 & $9.1 \%$ \\
\hline $\begin{array}{c}\text { Rib resection with decortication with } \\
\text { excision biopsy }\end{array}$ & 4 & $9.1 \%$ \\
\hline Total & $\mathbf{4 4}$ & $\mathbf{1 0 0 . 0} \%$ \\
\hline
\end{tabular}

Table 1. Type of Operation done among Chronic Pleural Empyema Patients

\begin{tabular}{|c|c|c|c|c|c|}
\hline Gender & \multicolumn{5}{|c|}{ Weight (Kg) } \\
\hline & $\begin{array}{c}\text { At } \\
\text { Enrolment }\end{array}$ & $\begin{array}{c}\mathbf{2} \\
\text { Weeks }\end{array}$ & $\begin{array}{c}\mathbf{6} \\
\text { Weeks }\end{array}$ & $\begin{array}{c}\mathbf{1 2} \\
\text { Weeks }\end{array}$ & $\begin{array}{c}\mathbf{2 4} \\
\text { Weeks }\end{array}$ \\
\hline & Mean \pm SD & $\begin{array}{c}\text { Mean } \pm \\
\text { SD }\end{array}$ & $\begin{array}{c}\text { Mean } \pm \\
\text { SD }\end{array}$ & $\begin{array}{c}\text { Mean } \pm \\
\text { SD }\end{array}$ & $\begin{array}{c}\text { Mean } \pm \\
\text { SD }\end{array}$ \\
\hline Male & $39.63 \pm 3.7$ & $\begin{array}{c}40.57 \pm \\
3.7\end{array}$ & $\begin{array}{c}41.74 \\
\pm 3.9\end{array}$ & $\begin{array}{c}43.30 \\
\pm 4.1\end{array}$ & $\begin{array}{c}46.0 \\
\pm 4.6\end{array}$ \\
\hline Female & $35.09 \pm 4.5$ & $\begin{array}{c}35.79 \pm \\
4.5\end{array}$ & $\begin{array}{c}37.09 \\
\pm 5.1\end{array}$ & $\begin{array}{c}38.20 \\
\pm 4.9\end{array}$ & $\begin{array}{c}40.6 \\
\pm 5.7\end{array}$ \\
\hline Total & $\begin{array}{c}\mathbf{3 6 . 9 5} \pm \\
\mathbf{4 . 7}\end{array}$ & $\begin{array}{c}\mathbf{3 7 . 7 4} \pm \\
\mathbf{4 . 8}\end{array}$ & $\begin{array}{c}\mathbf{3 8 . 9 9} \pm \\
\mathbf{5 . 1}\end{array}$ & $\begin{array}{c}\mathbf{4 0 . 2 9} \pm \\
\mathbf{5 . 2}\end{array}$ & $\begin{array}{c}\mathbf{4 2 . 8 3} \\
\mathbf{\pm 5 . 9}\end{array}$ \\
\hline $\begin{array}{c}\text { Student's 't' } \\
\text { Test Value }\end{array}$ & 3.502 & 3.677 & 3.249 & 3.586 & 3.277 \\
\hline P-Value & $\begin{array}{c}0.001 \\
\text { (HS) }\end{array}$ & $\begin{array}{c}0.001 \\
\text { (HS) }\end{array}$ & $\begin{array}{c}0.002 \\
(\mathrm{HS})\end{array}$ & $\begin{array}{c}0.001 \\
\text { (HS) }\end{array}$ & $\begin{array}{c}0.002 \\
(\mathrm{HS})\end{array}$ \\
\hline
\end{tabular}

Table 2. Weight of Chronic Pleural Empyema Patients after Thoracoplasty at different Time Interval

\begin{tabular}{|c|c|c|}
\hline Chest X-Ray Findings & Nos. & \% \\
\hline Mild collapse with hydro-pneumothorax & 4 & $9.1 \%$ \\
\hline $\begin{array}{c}\text { Moderate collapse with hydro- } \\
\text { pneumothorax }\end{array}$ & 25 & $56.8 \%$ \\
\hline $\begin{array}{c}\text { Near complete collapse with hydro- } \\
\text { pneumothorax }\end{array}$ & 15 & $34.1 \%$ \\
\hline Total & $\mathbf{4 4}$ & $\begin{array}{c}\mathbf{1 0 0 . 0} \\
\mathbf{\%}\end{array}$ \\
\hline
\end{tabular}

Table 3. Pre-operatively Chest X-Ray Findings among Chronic Pleural Empyema Patients 


\begin{tabular}{|c|c|c|c|c|c|}
\hline Chest X-Ray Findings & Post-OP & 2 Weeks & 6 Weeks & 12 Weeks & 24 Weeks \\
\hline & $\mathrm{N}(\%)$ & $\mathrm{N}(\%)$ & $\mathrm{N}(\%)$ & $\mathrm{N}(\%)$ & $\mathrm{N}(\%)$ \\
\hline No dead space with no hydro-pneumothorax & $2(4.5 \%)$ & $7(15.9 \%)$ & $24(54.5 \%)$ & $31(70.5 \%)$ & $32(72.7 \%)$ \\
\hline Mild dead space with no hydro-pneumothorax & $42(95.5 \%)$ & $37(84.1 \%)$ & $20(45.5 \%)$ & $13(29.5 \%)$ & $12(27.3 \%)$ \\
\hline Table 4. Postoperatively Chest X-Ray Findings at different Time Interval among Chronic Pleural Empyema Patients \\
\hline
\end{tabular}

\begin{tabular}{|c|c|c|c|c|c|}
\hline CM- Column Movement & 24 Hrs. & 7 Days & 14 Days & 4 Weeks & 6 Weeks \\
\hline & $\mathrm{N}(\%)$ & $\mathrm{N}(\%)$ & $\mathrm{N}(\%)$ & $\mathrm{N}(\%)$ & $\mathrm{N}(\%)$ \\
\hline Less than 5 cm & - & - & - & - & $\mathbf{3 5}(79.5 \%)$ \\
\hline $5-10 \mathrm{~cm}$ & - & - & $4(9.1 \%)$ & $30(68.2 \%)$ & $5(11.4 \%)$ \\
\hline $10-15 \mathrm{~cm}$ & $28(63.6 \%)$ & $28(63.6 \%)$ & $34(77.3 \%)$ & $14(31.8 \%)$ & $4(9.1 \%)$ \\
\hline More than 15 cm & $16(36.4 \%)$ & $16(36.4 \%)$ & $6(13.6 \%)$ & - & - \\
\hline
\end{tabular}

\begin{tabular}{|c|c|c|c|c|c|}
\hline CM- Column Movement & 24 Hrs. & 7 Days & 14 Days & 4 Weeks & 6 Weeks \\
\hline & N (\%) & N (\%) & N (\%) & N (\%) & N (\%) \\
\hline Less than 5 cm & - & - & - & $8(18.2 \%)$ & $\mathbf{3 6}(\mathbf{8 1 . 8 \% )}$ \\
\hline $5-10 \mathrm{~cm}$ & - & $1(2.3 \%)$ & $18(40.9 \%)$ & $27(61.4 \%$ & $6(13.6 \%)$ \\
\hline $10-15 \mathrm{~cm}$ & $9(20.5 \%)$ & $8(18.2 \%)$ & $21(47.7 \%)$ & $7(15.9)$ & $2(4.5 \%)$ \\
\hline More than $15 \mathrm{~cm}$ & $35(79.5 \%)$ & $35(79.5 \%)$ & $5(11.4 \%)$ & $2(4.5 \%)$ & - \\
\hline
\end{tabular}

\begin{tabular}{|c|c|c|c|c|c|}
\hline AL- Apical Leak & 24 Hrs. & 7 Days & 14 Days & 4 Weeks & 6 Weeks \\
\hline & N (\%) & N (\%) & N (\%) & N (\%) & N (\%) \\
\hline AL Absent on Coughing also & - & - & - & $26(59.1 \%)$ & $39(88.6 \%)$ \\
\hline AL with coughing & $26(59.1 \%)$ & $26(59.1 \%)$ & $37(84.1 \%)$ & $13(29.5 \%)$ & $1(2.3 \%)$ \\
\hline AL with deep expiration & $13(29.5 \%)$ & $13(29.5 \%)$ & $2(4.5 \%)$ & $1(2.3 \%)$ & $4(9.1 \%)$ \\
\hline AL with normal expiration & $5(11.4 \%)$ & $5(11.4 \%)$ & $5(11.4 \%)$ & $4(9.1 \%)$ & - \\
\hline \multicolumn{7}{|c}{ Table 6a. Air Leak from Straight Apical ICD } \\
\hline
\end{tabular}

\begin{tabular}{|c|c|c|c|c|c|}
\hline AL- Apical Leak & 24 Hrs. & 7 Days & 14 Days & 4 Weeks & 6 Weeks \\
\hline & N (\%) & N (\%) & N (\%) & N (\%) & N (\%) \\
\hline AL Absent on coughing also & $2(4.5 \%)$ & $2(4.5 \%)$ & $29(65.9 \%)$ & $39(88.6 \%)$ & $42(95.5 \%)$ \\
\hline AL with coughing & $31(70.5 \%)$ & $31(70.5 \%)$ & $10(22.7 \%)$ & $5(11.4 \%)$ & $2(4.5 \%)$ \\
\hline AL with deep expiration & $6(13.6 \%)$ & $6(13.6 \%)$ & $5(11.4 \%)$ & - & - \\
\hline AL with normal expiration & $5(11.4 \%)$ & $5(11.4 \%)$ & - & - & - \\
\hline \multicolumn{7}{|c|}{ Table 6b. Air Leak from Basal Angle ICD } \\
\hline
\end{tabular}

\section{DISCUSSION}

In past around 1890 rib resection was performed to decrease the size of thoracic cavity for empyema by Simon, Estlander and Schede, 17,18 to achieve compression of pulmonary parenchyma and collapse of pleural cavity as development of collapse therapy for Tuberculosis. John Alexander ${ }^{2}$ developed modern extrapleural posterolateral subperiosteal thoracoplasty as collapse therapy. They achieved cavity closure in $93 \%$ of survivors and operative mortality in about $10 \%$. With anti-tubercular treatment which effectively began in around 1950s, the pulmonary collapse therapy obsoleted. With the emergence of resistance from anti-tubercular drugs, recurrence rate and incidence of chronic empyema increased markedly. This lead to re-explore the various modalities of treatment including old as well as new one. So the dead space obliteration with identification and closure of bronchopleural fistula are the two major issues which require to be addressed. For dead space obliteration of pleural cavity, old procedures like pleural tenting, pneumoperitoneum formation, open window thoracostomy, phrenic nerve block and Clagett procedure are again being used.

Pleural tenting is an old method which is used to reduce the apical pleural space, which was first described by Miscall et al that has recently regained popularity. ${ }^{19,20,21}$
In the year 1924, Reich and colleagues first described the use of Pneumoperitoneum for patient with emphysema. Pneumoperitoneum is safe and effective procedure performed with the aid of imaging exams to guide the introduction of air. $22,23,24$

Open window thoracostomy is an ideal method for draining the septic pleural cavity in patients with empyema after pulmonary resection, especially in patients with postpneumonectomy bronchopleural fistula. ${ }^{11,12,13,25}$

Phrenic nerve block is used as temporary reduction of pleural cavity by raising the dome of diaphragm, which is contraindicated in patients with limited lung function. ${ }^{26}$

Clagett procedure is a two-stage procedure, which begins with open pleural damage and re-suturing of bronchial stump followed by packing of space with once or twice a day dressing with quarter strength Dakin's solution or povidoneiodine solution 20: 1 . Second stage involve the filling of pleural space with an antiseptic solution (DAB's solution) followed by water tight wound shutting. ${ }^{27}$

For identification and closure of bronchopleural fistula, 3 modalities like Endoscopic management, Video-Assisted Thoracoscopic Surgery (VATS) and Open Surgical procedure are in use. Endoscopic management is primarily diagnostic, but now therapeutic as well is a bridge to definitive 
surgery.28-30 The main benefit of VATS are better visualisation, which allow secure fixation of vascularised graft and decreased retraction of thoracic cage so postoperative pain is less and morbidity is reduced.

Early bronchopleural fistula requires urgent intervention with principle of surgical bronchopleural fistula repair, that is maintenance of vascularity as well as keep the short bronchial stump once the pleural cavity is clean. ${ }^{12,25,26,31,32}$

Late bronchopleural fistula requires either Clagett procedure or trans-sternal transpericardial approach. As Clagett procedure is multistep, prolonged and associated with high morbidity, the trans-sternal transpericardial approach which was initially described by Abruzzini is an option to avoid entering in a previously manipulated and diseased inflammatory cavity. $33,34,35$

So, the author found dead space closed reduction thoracoplasty has operative equivalence with minimal untoward consequences and improved psychosocial health when compared with open window thoracostomy. Its implication in early young age group of chronic empyema thoracis patients is highly demanding.

\section{CONCLUSION}

So, the author found that dead space closed reduction thoracoplasty has operative equivalence with minimal untoward consequences and improved psychosocial health when compared with open window thoracostomy. This study was done at a single centre with limited resource setting. So, author propose large multi-centric study to address the above issue more precisely.

\section{REFERENCES}

[1] Somers J, Faber LP. Historical development in the management of empyema. Chest Surg Clin N Am 1996;6(3):403-18.

[2] Alexander J. The surgery of pulmonary tuberculosis. Philadelphia: Lea \& Febiger 1925.

[3] Asamura H, Naruke T, Tsuchiya $R$, et al. Bronchopleural fistulas associated with lung cancer operations. Univariate and multivariate analysis of risk factors, management and outcome. J Thorac Cardiovasc Surg 1992;104(5):1456-64.

[4] Gaur P, Dunne R, Colson YL, et al. Bronchopleural fistula and the role of contemporary imaging. J Thorac Cardiovasc Surg 2014;148(1):341-7.

[5] Wright CD, Wain JC, Mathisen DJ, et al. Postpneumonectomy bronchopleural fistula after sutured bronchial closure: incidence, risk factors and management. J Thorac Cardiovasc Surg 1996;112(5):1367-71.

[6] Anderson TM, Miller JI. Use of pleura, azygos vein, pericardium and muscle flaps in tracheobronchial surgery. Ann Thorac Surg 1995;60(3):729-33.

[7] Pairolero PC, Trastek VF, Allen MS. Empyema and bronchopleural fistula. Ann Thorac Surg 1991;51(1): 157-8.

[8] Puskas JD, Mathisen DJ, Grillo HC, et al. Treatment strategies for broncho-pleural fistula. J Thorac Cardiovasc Surg 1995;109(5):989-95, discussion 9956.

[9] Allen MS, Deschamps C, Trastek VF, et al. Bronchopleural fistula. Chest Surg Clin 1992:823.
[10] Westcott JL, Volpe JP. Peripheral bronchopleural fistula: CT evaluation in 20 patients with pneumonia, empyema or postoperative air leak. Radiology 1995;196(1):175-81.

[11] Robinson S. The Treatment of chronic nontuberculous chronic emyeme. Surg Gynecol Obstet 1912;22:257.

[12] Shamji FM, Ginsberg RJ, Cooper JD, et al. Open window thoracostomy in the management of post pneumonectomy empyema with or without bronchopleural fistula. J Thorac Cardiovasc Surg 1983;86(6):818-22.

[13] Eloesser L. An operation for tuberculous empyema. Surg Gynecol Obstet 1935;60(1):1096-7.

[14] García-Yuste M, Ramos G, Duque JL, et al. Openwindow thoracostomy and thoracomyoplasty to manage chronic pleural empyema. Ann Thorac Surg 1998;65(3):818-22.

[15] Hopkins RA, Ungerleider RM, Staub EW, et al. The modern use of thoracoplasty. The Annals of Thoracic Sugery 1985;40(2):181-7.

[16] Dewan RK, Singh S, Kumar A, et al. Thoracoplasty: an obsolete procedure? Indian J chest Dis Allied Sci 1999;41(2):83-8.

[17] Mead RH. Surgery for pulmonary tuberculosis. In a history of thoracic surgery. Springfield, Illinois: Thomas 1961: p. 98-174.

[18] Gaensler EA. The surgery for pulmonary tuberculosis. Am Rev Repair Dis Suppl 1982;125:73.

[19] Miscall L, Duffy RW, Nolan RB, et al. The pleural tent as a simultaneous tailoring procedure in combination with pulmonary resection. Am Rev Tuberc 1956;73(6):831-52.

[20] Hansen JL. Parietal pleurolysis (the pleural tent) as a simultaneous space-reducing procedure in combination with pulmonary resection. Acta Chir Scand 1957;112(6):485-8.

[21] Uzzaman MM, Robb DJ, Mhandu PC, et al. A metaanalysis assessing the benefits of concomitant pleural tent procedure after upper lobectomy. Ann Thorac Surg 2014;97(1):365-72.

[22] Reich L. Der Einfluss des Pneumoperitoneums auf das Lungen-emphysem. Wien Arch Finn Med 1924;8:24560.

[23] Podgaetz E, Berger J, Small J, et al. Therapeutic Pneumoperitoneum: Relevant or Obsolete in 2015? Thorac Cardiovasc Surg 2017;65(5):375-81.

[24] Cerfolio RJ, Holman WL, Katholi CR. Pneumoperitoneum after concomitant resection of the right middle and lower lobes (bilobectomy). Ann Thorac Surg 2000;70(3):942-6, discussion 946-7.

[25] Clagett OT, Geraci JE. A procedure for the management of postpneumonectomy empyema. J Thorac Cardiovasc Surg 1963;45:141-5.

[26] Murthy SC. Air leak and pleural space management. Thorac Surg Clin 2006;16(3):261-5.

[27] Clagett OT. Changing aspects of the etiology and treatment of pleural empyema. Surg Clin North Am 1973;53(4):863-6. 
[28] Hollaus PH, Lax F, Janakiev D, et al. Endoscopic treatment of postoperative bronchopleural fistula: experience with 45 cases. Ann Thorac Surg 1998;66(3):923-7.

[29] Cardillo G, Carbone L, Carleo F, et al. The rationale for treatment of postresectional bronchopleural fistula: analysis of 52 patients. Ann Thorac Surg 2015;100(1):251-7.

[30] Scappaticci E, Ardissone F, Ruffini E, et al. As originally published in 1994: postoperative bronchopleural fistula: endoscopic closure in 12 patients. Updated in 2000. Ann Thorac Surg 2000;69(5):1629-30.

[31] Pairolero PC, Arnold PG, Trastek VF, et al. Postpneumonectomy empyema. The role of intrathoracic muscle transposition. J Thorac Cardiovasc Surg 1990;99(6):958-66, discussion 966-8.
[32] Zanotti G, Mitchell JD. Bronchopleural fistula and empyema after anatomic lung resection. Thorac Surg Clin 2015;25(4):421-7.

[33] Abruzzini P. Tratamento chirurgico delle fistulae del broncho principale consecutive pneumonectomia per tubercolosi. Chir Thorac 1961;14:65-71.

[34] Ginsberg RJ, Pearson FG, Cooper JD, et al. Closure of chronic postpneumonectomy bronchopleural fistula using the transsternal trans pericardial approach. Ann Thorac Surg 1989;47:231-5.

[35] Dal Agnol G, Vieira A, Oliveira R, et al. Surgical approaches for bronchopleural fistula. Shanghai Chest 2017;1:14. 